NASA Technical Memorandum 103280

AIAA-90-2578

\title{
Low Power Arcjet Performance
}

Francis M. Curran and Charles J. Sarmiento

Lewis Research Center

Cleveland, Ohio

Prepared for the

21st International Electric Propulsion Conference cosponsored by the AIAA, DGLR, and JSASS

Orlando, Florida, July 18-20, 1990 


\title{
Low Power Arcjet Performance
}

\author{
Francis M. Curran and Charles J. Sarmiento \\ NASA Lewis Research Center \\ 21000 Brookpark Road, M.S. 500-219 \\ Cleveland, Ohio 44135
}

\begin{abstract}
An experimental investigation was performed to evaluate arcjet operation at low power. A standard, $I$ $\mathrm{kW}$, constricted arcjet was run using nozzles with three different constrictor diameters. Each nozzle was run over a range of current and mass flow rates to explore stability and performance in the low power regime. A standard pulse-width modulated power processor was modified to accomodate the high operating voltages required under certain conditions. Stable, reliable operation at power levels below $0.5 \mathrm{~kW}$ was obtained at efficiencies between 30 and 40 percent. The operating range was found to be somewhat dependent on constrictor geometry at low mass flow rates. Quasi-periodic voltage fluctuations were observed at the the low power end of the operating envelope. The nozzle insert geometry was found to have little effect on the performance of the device. The observed performance levels show that specific impulse levels above 350 seconds can be obtained at the $0.5 \mathrm{~kW}$ power level.
\end{abstract}

\section{Introduction}

Arcjet thrusters were the subject of a government-sponsored research and development effort that started in the mid-1950's. The primary focus of this effort was on providing primary propulsion on major NASA missions. In general, development programs in this period assumed both the availability of space-based nuclear power systems and cryogenic hydrogen storage. Because of these assumptions, most of the hardware development effort was concentrated on devices that operated at the $30 \mathrm{~kW}$ power level and used hydrogen as the propellant ${ }^{1-4}$. Some of the resources were directed toward the development of thrusters that operated in the 1 $2 \mathrm{~kW}$ range and these efforts resulted in a successful, uninterrupted 150 hour lifetest of a 2 $\mathrm{kW}$ hydrogen thruster at the Plasmadyne Corporation $^{5}$ and in the fabrication of a $1 \mathrm{~kW}$ flight system designed as a candidate for the Space Electric Rocket Test (SERT) program. 6,7 Ground tests of the latter unit indicated design problems and the system was shelved. Other propellants, including ammonia, were tried using hardware from the $1 \mathrm{~kW}$ program with little success. This progam was terminated in the mid1960s and a final review was published by Wallner and Czika in 1965.8

The evolution of commercial communications satellites has resulted in a need for improved auxiliary propulsion system performance and this, in turn, has resulted in the re-evaluation of arcjet systems. Over the past seven years low power arcjet research efforts, sponsored both by NASA and by private

\footnotetext{
Copyright (C) 1990 by the American Institute of Aeronautics and Astronautics, Inc. No copyright is asserted in the United States under Title 17, U.S. Code. The U.S. Government has a royalty-free license to exercise all rights under the copyright claimed herein for Governmental purposes. All other rights are reserved by the copyright owner.
}

industry, have been directed toward the development of a system to replace the state-ofart resistojet and bi-propellant systems now in use for north-south stationkeeping (NSSK) on geosynchronous communications satellites. To match mission profiles and satellite systems, current programs have focused on arcjet systems that will operate on hydrazine decomposition products at power levels between 1 and $2 \mathrm{~kW}$. Laboratory tests have demonstrated stable, reliable operation under these conditions at specific impulse levels in the 450 - 550 second range. $9-11$ An automated, cyclic arcjet lifetest was performed 12 and a flight-type $1.4 \mathrm{~kW}$ system has been assembled and tested. ${ }^{13,14}$ In addition, the effects of plume impacts have been investigated 15,16 and a system impact assessment is in progress. 17

While current program results indicate that the $1 \mathrm{~kW}$ class arcjet is nearing flight readiness, other applications may require extension of arcjet technology beyond the $1 \mathrm{~kW}$ class. One potential area of interest is the use of arcjets for propusion functions on power-limited satellites. While next-generation communications satellites are expected to generate 5 to $10 \mathrm{~kW}$ of electrical power, there will be a continuing need for lightweight satellite systems that will be limited to power levels on the order of $2 \mathrm{~kW}$ and below. ${ }^{18}$

This paper describes the results of an experimental program aimed at the development of low power $(<1 \mathrm{~kW})$ arcjet thrusters. In this program, a number of arcjet anodes were tested to provide information on operating characteristics 
and performance associated with this power range. Hydrogen/nitrogen mixtures were used to simulate hydrazine decomposition products and an existing power processor ${ }^{19}$ was modified to allow operation at low current level over a wide range of voltages.

\section{Apparatus}

Arcjet Thruster. A cross-sectional schematic of the arcjet thruster used in this study is shown in Figure 1. The thruster was modular and similar to thrusters used in many recent tests. $20,21,22$ A cutaway of the nozzle is shown in the figure and the dimensions of the three nozzles used in the tests are given in Table 1. The nozzles were made from 2 percent thoriated tungsten. Both the converging and diverging sides of each nozzle were conical with half angles of 30 and 20 degrees, respectively. On each nozzle, the inlet to the converging side was $6.4 \mathrm{~mm}$ in diameter, the diameter at the exit plane was $9.5 \mathrm{~mm}$, and the length of the constrictor was $0.25 \mathrm{~mm}$. As listed in Table 1, the constrictor diameters of the inserts were $0.38,0.51$, and $0.64 \mathrm{~mm}$. These will be referred to as nozzle inserts 1 through 3 , respectively. The overall length of the anode insert was adjusted as necessary to accomodate the changes in constrictor diameter between inserts.

The cathode used in the tests was made from a 2 percent thoriated tungsten rod $3.2 \mathrm{~mm}$ in diameter and $190 \mathrm{~mm}$ in length. The tip of the cathode was conical with a $30^{\circ}$ angle to match the converging side of the nozzle. The propellant injection disk provided tangential swirl of the propellant in the chamber upstream of the constrictor to stabilize the arc. The disk was made from molybdenum and had a center bore 6.4 $\mathrm{mm}$ in diameter. The twin injection ports were $0.51 \mathrm{~mm}$ in diameter.

The cathode to anode spacing, or arc gap, was set by moving the cathode forward until it contacted the anode and then withdrawing it $\mathbf{0 . 5 8}$ $\mathrm{mm}$

Both the front and rear insulators were made from high purity boron nitride. The front insulator was nominally $12.4 \mathrm{~mm}$ in diameter. Rectangular grooves were cut along the length of its exterior to allow propellant flow between the insulator and the stainless steel anode housing. A $3.2 \mathrm{~mm}$ hole was drilled through the center of the insulator to center the cathode. A modified stainless steel compression fitting was used to insert the cathode through the rear insulator of the thruster and clamp it in place. A threaded, center-drilled holding bolt inserted into the interior of the insulator secured this fitting. The rear insulator also contained an inconel spring and a boron nitride compression plunger. Two molybdenum plates were used to hold the rear insulator and the anode housing together. Clearances were adjusted so that the spring was in compression when the arcjet was assembled. Graphite gaskets were placed at critical surfaces within the thruster and the force of the spring provided gas tight seals.

The propellant tube entered the thruster through the side of the rear insulator and threaded into a stainless steel anchor. The tube and anchor were isolated from the cathode by an alumina sleeve.

Test Facility. All of the tests were performed in a $0.91 \mathrm{~m}$ diameter test section connected to a main vacuum tank through a gate valve. The main vacuum tank is $1.5 \mathrm{~m}$ in diameter and $5 \mathrm{~m}$ in length. Pumping for the vacuum tank was provided by four diffusion pumps with a combined capacity of 120,000 LPS, backed by a rotary blower and two mechanical roughing pumps. At the maximum propellant flow rate the tank pressure was maintained at approximately $0.65 \mathrm{~Pa}\left(5 \times 10^{-4}\right.$ torr $)$. A calibrated flexure-type thrust stand was used to obtain thrust measurements. This stand employed a linear variable displacement transducer (LVDT) and has been described in detail elsewhere. 20 The arcjet mount was mounted on a water-cooled support and the stand was enclosed by a water-cooled copper casing to minimize thermal drift from heat conducted and radiated by the arcjet.

Propellant Supply System. To simulate the decomposition products of hydrazine, the arcjet was run on mixtures of hydrogen and nitrogen with a molar mixture ratio of 2 to 1 . Thermal conductivity-type mass flow controllers were used to meter the gas. A calibration tank was incorporated into the flow system to allow periodic, in-situ flow calibrations.

Power Processing and Measurement. A standard pulse-width modulated power processing unit (PPU) was modified to allow arcjet operation in the $150-200$ volt range. During the first series of nozzle tests it was discovered that the output voltages required $(150-200 \mathrm{~V})$ were above the supplies normal capacity. For this, the secondary winding on the supply's output 
transformer was reworked. The output current ripple was also reduced. Oscilloscope traces showing the current ripple at both 2 and 8 amps are shown in Figures 2 (a) and (b) respectively. These data were obtained with the PPU driving a $10 \mathrm{ohm}$ resistive load. The supply incorporated a pulsed, high voltage starting circuit.

A Hall-effect current probe was used to measure the current to the arcjet and an isolated digital multimeter was used to measure arc voltage.

\section{Experimental Procedure}

Burn-in/Test Sequence. Arcjets commonly require a burn-in period before stable, consistent operation is obtained. For this, the arcjet was assembled with a freshly tipped cathode and nozzle insert $2\left(D_{c}=0.51 \mathrm{~mm}\right)$ and operated in the vacuum facility for approximately 20 hours. For tests of each nozzle insert, the arcjet was reassembled with the same cathode and run until consistent operation was observed before performance measurements were taken (approximately one hour).

Each nozzle insert was tested at four mass flow rates between $2.48 \mathrm{E}-5 \mathrm{~kg} / \mathrm{s}$ and $4.97 \mathrm{E}-5$ $\mathrm{kg} / \mathrm{s}$. The high end of this range is typical of the beginning of life mass flow expected in a blowdown system while the low end of the range is about $40 \%$ below the end of life value. In a typical test sequence, the thruster was started at the highest mass flow rate with the PPU preset to $7 \mathrm{~A}$. The current level was then decreased in 1 A decrements until the thruster would no longer operate or operation became erratic. At each current level the thruster was allowed to come to steady state. The $7 \mathrm{~A}$ test point was then repeated in order to determine whether significant changes had occured over the course of the test. The flow rate was then reduced and the test series was repeated. Nozzle insert 3 was run at current levels above $7 \mathrm{~A}$ for comparison with data obtained in previous tests.

Calibrations. Calibrations of both the nitrogen and the hydrogen mass flow controllers were performed before the start of testing and were repeated periodically during the test phase.

The thrust stand was calibrated before each test run using a set of known free weights that were suspended from the thruster mount. At the conclusion of each test sequence, the propellant flow was turned off and the LVDT zero checked while the thruster was still hot. In some cases, a slight zero offset $(<1 \%)$ was observed and this was accounted for by averaging the calibration readings obtained before and after the tests.

The Hall effect current probe was calibrated before each run using a current shunt in the line of a laboratory dc power supply.

\section{Results and Discussion}

The objective of this investigation was to obtain a preliminary assessment of arcjet operating characteristics and performance at power levels well below $1 \mathrm{~kW}$. As a basis for comparison, the low power operating range of a modular, constricted, laboratory arcjet was mapped using a nozzle insert that had been used as the baseline design in other tests. Two other nozzles with smaller constrictor diameters were then run in order to examine the effects of constrictor geometry and chamber pressure on low power arcjet operation.

Operating Characteristics. Data taken in each of the test cases are shown in Tables 2 through 4. The current-voltage (I-V) characteristics observed with the three nozzle inserts are shown in Figure 3. For clarity, only the data taken at a flow rate of $3.73 \mathrm{E}-5 \mathrm{~kg} / \mathrm{s}$ are shown. Similar trends were observed at the other flow rates. These I-V characteristics are similar to those observed in previous tests of other, similar arcjets in this facility. ${ }^{10,12,22}$ A thruster used in a recent test of the effects of nozzle shape on arcjet operation was functionally identical to the arcjet run in this test with nozzle insert 3.22 At identical operating points (i.e., identical current and mass flow rates), the arc voltage levels observed agreed to within 1 percent.

To obtain lower power operation it was necessary to decrease both the arc current and the mass flow rates to levels below those used in the previously cited reports. As expected, low current operation required high operating voltages and, for the smallest constrictor diameter, a PPU output voltage of $140-200$ volts was required.

As noted in a previous section, low power operation was obtained at each operating point (i.e., mass flow rate and constrictor geometry) by lowering the current to the arcjet. At each operating point, the current was lowered until the thruster no longer exhibited stable operation. 
Typically, the instabilities observed took the form of quasi-periodic voltage fluctuations that occurred more frequently with decreasing current at a set mass flow rate. The cause of these oscillations is not well understood. It possible that they arise from motion of the electrode attachment points. Similar voltage oscillations have commomly followed startup in prior arcjet tests and are often accompanied by motion in the visible plume. In steady state operation the cathode emits from a small molten tip ${ }^{21}$ and the anode attachment is diffuse on the nozzle surface. ${ }^{23}$ It is possible that either or both of these conditions may change at low current levels resulting in mobile attachment points and the observed fluctuations in the arcjet voltage.

Repeatability and Accuracy. As noted in the preceeding section on test procedure, selected test points were repeated in each test sequence to ensure that consistent results were obtained. In addition, to quantify the data scatter experimentally, one operating point (i.e., fixed current and mass flow rate) in the nozzle insert 3 test sequence was repeated seven times on three different days. The data from these test points are contained in Table 2. Statistical analysis of these data showed that the standard deviations (N1) of the measured values of voltage and thrust, as well as in the performance values (i.e., specific impulse and efficiency) were less than one percent of the average values.

Low Power Performance Characteristics. Figure 4 shows a plot of specific impulse versus power for all the operating points examined. From the figure, performance was relatively independent of the differences in nozzle geometry between inserts. The specific impulse at each mass flow rate shows a linear increase with power. This indicates that at a given flow rate, accurate performance predictions can be made over a wide range of input power. The data also show that the lowest power operating points were obtained at the middle flow rates with the mid-sized nozzle insert at the two amp current level. This may have been an experimental artifact, as there were day-to-day variations in the observed range of operational stability. A full explanation of this will require a much more detailed study including the effects of injection velocity and the arcjet/PPU interface. Finally, the plot shows that specific impulse values above 350 seconds are be obtainable at the $\mathbf{0 . 5}$ $\mathrm{kW}$ power level.

Figure 5(a) shows a plot of specific impulse versus specific power for all of the test points.
At specific powers below about $17,000 \mathrm{~kJ} / \mathrm{kg}$ the specific impulse is directly proportional to specific power and the data taken at the different mass flow rates fall in a narrow band. At higher specific powers this relationship changes and the specific impulse at a given specific power is mass flow rate dependent. This is shown in Figure 5(b). This figure includes the data from only the highest and the lowest flow rates. At a given specific power, the curve for the lower mass flow rate is significantly below that for the highest mass flow rate. When plotted, the other two mass flow rates fall between the highest and lowest in monotonic order. The observed trend indicates that at least one efficiency loss mechanism is increasing as the flow rate is decreased. Arcjet efficiency, as defined in Appendix A, is plotted versus specific power in Figure 6 for both the highest and lowest mass flow rates. This shows the decrease in efficiency with specific power at the lower flow rate indicated in Figure 5 (b). For the lower mass flow rate the noted decrease in efficiency appears to be directly proportional to specific power. At the higher mass flow rate the efficiency is relatively independent of specific power for specific powers greater than approximately $17,000 \mathrm{~kJ} / \mathrm{kg}$.

In the arcjet, the electrons are accelerated by the electric field between the anode and the cathode and impart energy to the propellant though collisional processes. A portion of the input electrical energy is not converted to thrust. Frozen flow losses; electrode losses; and viscous, or frictional, losses account for a majority of the unrecovered energy. The noted decrease in arcjet operating efficiency with decreasing mass flow rate at a constant specific power indicates that one or more of these losses must increase as flow rate is reduced.

Frozen flow losses are a result of energy invested in ionization, excitation, and molecular dissociation that is not thermalized by the nozzle exit plane. A recent spectroscopic investigation of a low power arcjet indicates that the majority of this energy loss is due to dissociation. ${ }^{24}$ It is possible that increases in the rates of collisional processes that occur as mass flow rate is increased contribute to the observed behavior. Detailed information on both the electron energy distribution and relevant collision cross sections will be nessecary to fully evaluate this hypothesis.

Energy dissipated at the anode accounts for the major electrode loss. A majority of this 
energy is deposited by the electrons as they are absorbed at the anode surface. The total energy deposited depends on the current and conditions near the surface. Since the arcjet anode is radiatively cooled, it should be possible to quantify the contribution of this loss through a careful study of the radiant heat losses from the anode housing under various operating conditions.

As noted in a recent paper on arcjet nozzle phenomena, the arcjet flowfield is complex, ${ }^{22}$ and is not easily understood in the context of classical nozzle analysis. In these, the Reynolds number $(\mathrm{Re})$ is used to evaluate the relative importance of viscous effects in nozzle expansions. This is given by the equation:

$$
\operatorname{Re}=\rho V L / \mu(T)
$$

in which $\rho$ is the mass density, $V$ is the gas velocity, $\mu(T)$ is the viscosity, and $L$ is a characteristic body dimension. Experimental and theoretical studies of low Re flows indicate that viscous effects should be considered in flows typical of small electric thrusters such as resistojets. 25,26 Due to the large flowfield gradients and small physical dimensions in the arcjet, it is difficult to choose a characteristic body dimension and to assign appropriate values for the density and viscosity. If an average density is assumed, equation 1 can be rewritten as:

$$
\operatorname{Re}=4 \mathrm{~m} / \pi \mathrm{L} \mu(\mathrm{T})
$$

It would be expected that viscous losses would increase with decreasing Re but the exact dependence is quite sensitive to specific characteristics of the thruster such as geometry. Equation 2 indicates that, at a constant specific power, $R e$ decreases with decreasing mass flow rate if both the characteristic body dimension and the viscosity remain fairly constant. However, the dependence of these variables on the mass flow rate in the arcjet is unknown. Because of the lack of knowledge of flowfield characteristics, firm conclusions about frictional losses cannot be drawn at this time.

The data do indicate that at a fixed specific power, or a fixed power, specific impulse and efficiency increase and decrease, respectively, with decreasing mass flow rate. These trends increased with increasing specific power. It is clear that more detailed information on the characteristics of the arcjet flowfield will be required to separate relative effects of the important loss mechanisms.

\section{Concluding Remarks}

The major objective of this study was to demonstrate low power $(<1 \mathrm{~kW})$ arcjet operation and to document performance levels and operating characteristics in this operating range. Over the course of this study, several constrictor diameters were tested at a number of experimental conditions and a preliminary map of operating and performance characteristics for constricted arcjets at power levels below $1 \mathrm{~kW}$ was obtained. Stable, reliable operation below $0.5 \mathrm{~kW}$ was observed. From the observed performance levels, it appears that specific impulse levels above 350 seconds can be obtained at the $0.5 \mathrm{~kW}$ power level. The diameter of the constrictor was found to have very little effect on the performance of the device. At each mass flow rate, the performance was linearly related to the input power. In these preliminary tests the envelope of stability was somewhat different for each constrictor tested. A full understanding of this does not exist and will likely require more information about propellant injection and the dynamic arcjet/PPU interface. The higher voltages and lower currents necessary for low power operation will necessitate power processor modifications.

A trend observed in the relationship between specific impulse and specific power was noted which indicates that arcjet efficiency is affected by the mass flow rate. At the highest mass flow rates studied, the efficiency did not vary significantly with specific power. At the lowest mass flow rate, the efficiency decreased linearly with increasing specific power. More detailed information on microscopic flowfield characteristics will be necessary to fully evaluate the cause of this change. 


\section{Appendix A}

All arcjet efficiency values were calculated using the following equation:

$$
\begin{aligned}
\eta & =\frac{(1 / 2) \mathrm{m}\left(\mathrm{v}_{\mathrm{b}}\right)^{2}}{\mathrm{P}_{\mathrm{a}}+(1 / 2) \mathrm{m}\left(\mathrm{vd}_{\mathrm{d}}{ }^{2}\right.} \\
& =\frac{\left(\mathrm{I}_{\mathrm{gq}}\right)^{2}}{(2 / \mathrm{g})\left(\mathrm{P}_{\mathrm{d}} / \mathrm{m}\right)+\left(\mathrm{I}_{\mathrm{sp}}\right)^{2}}
\end{aligned}
$$

For this, the following notation was used:

$$
\begin{array}{ll}
\mathrm{g} \text { - } & \begin{array}{l}
\text { gravitational acceleration, } 9.8 \mathrm{~m} / \mathrm{sec}^{2} \\
\text { subscripts denoting hot and cold }
\end{array} \\
& \begin{array}{l}
\text { conditions } \\
\mathrm{I}_{\mathrm{sp}}-
\end{array} \\
\mathrm{m}- & \text { specific impulse, } \mathrm{sec} \\
\mathrm{P}_{\mathrm{a}}- & \text { mass flow rate, } \mathrm{kg} / \mathrm{sec} \\
\mathbf{v}- & \text { exhaust velocity, } \mathrm{m} / \mathrm{sec} \\
\eta & -\quad \text { thrust efficiency. }
\end{array}
$$

\section{References}

1. John, R. R.; Connors, J. F.; and Bennett, S.: "Thirty Day Endurance Test of a $30 \mathrm{~kW}$ Arcjet Engine," AIAA Paper 63-274, June 1963.

2. John, R. R.:"Thirty Kilowatt Plasmajet Rocket-Engine Development," RAD-TR-646, Avco Corp., Wilmington, MA, NASA CR-54044, 1964.

3. Todd, J. P.; and Sheets, R.E.: "Development of a Regeneratively Cooled 30-kW Arcjet Engine," AIAA Joumal, Vol. 3, No. 1, Jan. 1965, pp. 122-126.

4. Todd, J. P.: "30kW Arcjet Thruster Research," APL-TDR-64-58, Giannini Scientific Corp., Santa Ana, CA, Mar. 1964. (Avail. NTIS, AD-601534).

5. McCaughey, O. J.; Geldeman, W. A. , Jr.; and Muller, K.: "Research and Advanced Development of a $2 \mathrm{~kW}$ Arc-Jet Thrustor," (GRC-1646, Plasmadyne Corp,; NASA
Contract NAS3-2521), NASA CR-54035, 1963.

6. Greco, R.V.; and Stoner, W.A.: "Development of a Plasmajet Rocket Engine for Attitude Control," GRC-1341-A, Plasmadyne Corp., Santa Ana, CA, Dec. 1961.

7. Ducati, A. C., et. al.: "1-kW Arcjet-Engine System-Performance Test," J. Spacecraft Rockets, Vol. 1, No. 3, May-June 1964, pp. 327-332.

8. Wallner, L. E.; and Czika, J., Jr.: "Arcjet Thrustor for Space Propulsion," NASA TD D-2868, 1965.

9. Knowles, S. K.: "Arcjet Thruster Research and Technology, Phase II." NASA CR182276,1990 (to be published).

10. Hardy, T. L.; and Curran, F. M.: "Low Power dc Arcjet Operation with Hydrogen/Nitrogen/Ammonia Mixtures. AIAA Paper 87-1948, June 1987. (NASA TM-89876).

11. Knowles, S. C.; et. al. : "Performance Characterization of a Low Power Hydrazine Arcjet," AIAA Paper 87-1057, May 1987.

12. Curran, F. M.; and Haag, T. W.: "An Extended LIfe and Performance Test of a Low Power Arcjet. AIAA Paper 88-3106, July 1988. (NASA TM-100942).

13. Yano, S. E.; and Knowles, S. K.: "Simulated Flight Qualification Test of an Engineering Model Arcjet System, "presented at the 1989 JANNAF Meeting, Cleveland, Ohio, May 1989.

14. Knowles, S. K.; Yano, S. E.; and Audland, R. S.: "Qualification and Lifetesting of a Flight Design Hydrazine Arcjet System," to be presented at the 1990 International Electric Propulsion Conference, Orlando, FL, July 1989.

15. Carney, L. M.: "Evaluation of the Communications Impact of a Low Power Arcjet Thruster," AIAA Paper 88-3105, July 1988 (NASA TM-100926).

16. Ling, H.; et. al.: "Reflector Performance Degradation Due to an Arcjet Plume," 
Presented at the 1989 Antenna Applications Symposium, Monticello, IL, Sept. 1989.

17. Zafran, S.: "Arcjet System Integration Development Program," Final Report, NASA CR-185266, TRW, Inc., Redondo Beach, CA, (to be published).

18. Proceedings of the AIAA/DARPA Meeting on Lightweight Satellite Systems, Monterey, CA, August 1987.

19. Gruber, R. P.: "Power Electronics for a $1 \mathrm{~kW}$ Arcjet Thruster," AIAA Paper 86-1507, June 1986. (NASA TM-87340).

20. Haag, T. W.; and Curran, F. M.: "Arcjet Starting Reliability: A Multistart Test on Hydrogen/Nitrogen Mixtures." AIAA Paper 87-1061, May 1987. (NASA TM-89867).

21. Curran,F. M.; Haag, T. W.; and Raquet, J. F.: "Arcjet Cathode Phenomena," presented at the 1989 JANNAF Meeting, Cleveland, OH, May 1989. (NASA TM-102099).
22. Curran, F. M.; Sovie, A.; and Haag, T. W.: "Arcjet Nozzle Design Impacts," 1989 JANNAF Propulsion Meeting, Cleveland, OH. (NASA TM-102050).

23. Curran, F. M.; and Manzella, D. H.: "The Effect of Electrode Configuration on Arcjet Performance," AIAA Paper 89-2722, July 1989. (NASA TM-102346).

24. Manzella, D. H.; Curran, F. M.; and Zube, D. M. : "Preliminary Plume Characteristics of an Arcjet Thruster," AIAA Paper 902645, July 1990.

25. Rothe, D.: "Electron-Beam Studies of Viscous Flow in Supersonic Nozzles," AIAA Journal, Vol. 9, No. 5, May 1971, pp. 804-811.

26. Rae, W. J.: "Some Numerical Results on Viscous Low-Density Nozzle Flows in the Slender-Channel approximation," AIAA Journal. Vol. 9, No. 12, Dec. 1972, pp. 869-875.

Table 1. Nozzle insert dimensions.

$\begin{array}{cccc}\begin{array}{c}\text { Nozzle insert } \\ \text { number }\end{array} & \begin{array}{c}\text { Constrictor diameter, } \\ \mathrm{Dc}(\mathrm{mm})\end{array} & \begin{array}{c}\text { Constrictor length, } \\ \mathrm{Lc}(\mathrm{mm})\end{array} & \begin{array}{c}\text { Nozzle area } \\ \text { ratio }\end{array} \\ 1 & 0.38 & 0.25 & 625 \\ 2 & 0.51 & 0.25 & 352 \\ 3 & 0.64 & 0.25 & 225\end{array}$


Table 2. Data from tests with nozzle inser 1.

\begin{tabular}{|c|c|c|c|c|c|c|c|c|}
\hline & $\dot{m}\langle\mathrm{~kg} / \mathrm{s}\rangle$ & Current,A & Voltage, V & Power (kW) & Thrust (N) & Isp (s) & $\mathrm{P} / \dot{\mathrm{m}} \quad(\mathrm{kJ} / \mathrm{kg})$ & Elficiency \\
\hline 1 & $4.97 e-5$ & 7.0 & 143 & 1.00 & 0.200 & 411 & $2.02 \theta+4$ & 0.390 \\
\hline 2 & $4.97 e-5$ & 7.0 & 144 & 1.01 & 0.201 & 414 & $2.03 e+4$ & 0.393 \\
\hline 3 & $4.97 e-5$ & 6.0 & 149 & 0.90 & 0.191 & 393 & $1.80 e+4$ & 0.398 \\
\hline 4 & $4.97 e-5$ & 5.0 & 157 & 0.79 & 0.179 & 369 & $1.58 e+4$ & 0.396 \\
\hline 5 & $4.97 \mathrm{e}-5$ & 4.0 & 168 & 0.67 & 0.167 & 343 & $1.35 e+4$ & 0.398 \\
\hline 6 & $4.97 e-5$ & 3.0 & 185 & 0.55 & 0.154 & 316 & $1.11 e+4$ & 0.406 \\
\hline 7 & $4.97 e-5$ & 7.0 & 143 & 1.00 & 0.200 & 412 & $2.02 \theta+4$ & 0.392 \\
\hline 8 & $4.97 e-5$ & 7.0 & 143 & 1.00 & 0.200 & 411 & $2.02 e+4$ & 0.389 \\
\hline 9 & $4.97 e-5$ & 7.0 & 144 & 1.01 & 0.202 & 415 & $2.03 e+4$ & 0.395 \\
\hline 10 & $4.97 e-5$ & 7.0 & 146 & 1.02 & 0.203 & 417 & $2.06 \theta+4$ & 0.395 \\
\hline 11 & $4.97 e-5$ & 7.0 & 146 & 1.02 & 0.203 & 416 & $2.06 \theta+4$ & 0.391 \\
\hline 12 & $3.73 e-5$ & 7.0 & 134 & 0.93 & 0.162 & 443 & $2.51 \theta+4$ & 0.367 \\
\hline 13 & $3.73 e-5$ & 6.0 & 139 & 0.83 & 0.153 & 421 & $2.23 \theta+4$ & 0.371 \\
\hline 14 & $3.73 e-5$ & 5.0 & 145 & 0.73 & 0.145 & 397 & $1.95 e+4$ & 0.375 \\
\hline 15 & $3.73 e-5$ & 4.0 & 156 & 0.62 & 0.135 & 371 & $1.67 \theta+4$ & 0.381 \\
\hline 16 & $3.73 \theta-5$ & 3.0 & 170 & 0.51 & 0.125 & 342 & $1.37 \theta+4$ & 0.392 \\
\hline 17 & $3.11 \theta-5$ & 7.0 & 128 & 0.90 & 0.141 & 462 & $2.89 \theta+4$ & 0.347 \\
\hline 18 & $3.11 \theta-5$ & 6.0 & 132 & 0.80 & 0.134 & 439 & $2.56 \theta+4$ & 0.353 \\
\hline 19 & $3.11 \theta-5$ & 5.0 & 139 & 0.70 & 0.126 & 415 & $2.24 \theta+4$ & 0.358 \\
\hline 20 & 3.110 .5 & 5.0 & 139 & 0.69 & 0.125 & 409 & $2.23 \theta+4$ & 0.349 \\
\hline 21 & $3.110-5$ & 4.0 & 148 & 0.59 & 0.117 & 382 & $1.90 \theta+4$ & 0.357 \\
\hline 22 & 3.110 .5 & 3.0 & 162 & 0.48 & 0.107 & 350 & $1.56 \theta+4$ & 0.363 \\
\hline 23 & $2.4850-5$ & 5.0 & 131 & 0.65 & 0.106 & 435 & $2.630+4$ & 0.336 \\
\hline 24 & $2.485 e-5$ & 4.0 & 141 & 0.56 & 0.099 & 407 & $2.27 e+4$ & 0.341 \\
\hline 25 & $2.485 \theta-5$ & 3.0 & 156 & 0.47 & 0.092 & 379 & $1.88 \theta+4$ & 0.354 \\
\hline 26 & $2.485 e-5$ & 2.5 & 167 & 0.42 & 0.088 & 363 & $1.68 \theta+4$ & 0.364 \\
\hline 27 & $2.485 \theta-5$ & 6.0 & 124 & 0.75 & 0.110 & 451 & $3.00 \theta+4$ & 0.319 \\
\hline
\end{tabular}

Table 3. Data from tests with nozzle insert 2.

\begin{tabular}{|c|c|c|c|c|c|c|c|}
\hline mi $(\mathrm{kg} / \mathrm{s})$ & Current,A & Voltage,V & Power (kW) & Thrust (N) & Isp (s) & $\mathrm{P} / \dot{\mathrm{m}} \quad(\mathrm{kJ} / \mathrm{kg})$ & Efficiency \\
\hline $4.97 e-5$ & 7.0 & 134 & 0.935 & 0.189 & 389 & $1.880+4$ & 0.372 \\
\hline $4.97 e-5$ & 7.0 & 132 & 0.927 & 0.189 & 388 & $1.87 \theta+4$ & 0.375 \\
\hline $4.97 e-5$ & 6.0 & 138 & 0.829 & 0.179 & 368 & $1.67 e+4$ & 0.375 \\
\hline $4.97 e-5$ & 5.0 & 146 & 0.728 & 0.169 & 348 & $1.46 e+4$ & 0.380 \\
\hline $4.97 e-5$ & 4.0 & 156 & 0.625 & 0.157 & 323 & $1.26 \theta+4$ & 0.377 \\
\hline $4.97 e-5$ & 3.0 & 172 & 0.517 & 0.145 & 298 & $1.04 \theta+4$ & 0.385 \\
\hline $4.97 e-5$ & 7.0 & 133 & 0.928 & 0.188 & 387 & $1.87 \theta+4$ & 0.371 \\
\hline $3.73 e-5$ & 7.0 & 123 & 0.864 & 0.153 & 419 & $2.32 \theta+4$ & 0.354 \\
\hline $3.73 e-5$ & 6.0 & 129 & 0.777 & 0.146 & 401 & $2.080+4$ & 0.359 \\
\hline $3.73 e-5$ & 5.0 & 137 & 0.684 & 0.139 & 380 & $1.83 \theta+4$ & 0.365 \\
\hline $3.73 e-5$ & 4.0 & 148 & 0.592 & 0.130 & 355 & $1.59 e+4$ & 0.366 \\
\hline $3.73 e-5$ & 3.0 & 157 & 0.470 & 0.118 & 324 & $1.26 \theta+4$ & 0.380 \\
\hline $3.73 e-5$ & 2.0 & 180 & 0.359 & 0.106 & 291 & $9.62 \theta+3$ & 0.397 \\
\hline $3.73 e-5$ & 7.0 & 122 & 0.853 & 0.152 & 417 & $2.290+4$ & 0.355 \\
\hline $3.11 e-5$ & 7.0 & 115 & 0.806 & 0.132 & 432 & $2.59 e+4$ & 0.338 \\
\hline $3.11 \mathrm{e}-5$ & 6.0 & 121 & 0.724 & 0.126 & 415 & $2.33 \theta+4$ & 0.347 \\
\hline $3.11 e-5$ & 5.0 & 128 & 0.639 & 0.120 & 394 & $2.060+4$ & 0.352 \\
\hline $3.11 e-5$ & 4.0 & 138 & 0.553 & 0.112 & 368 & $1.78 e+4$ & 0.353 \\
\hline $3.11 \mathrm{e}-5$ & 3.0 & 154 & 0.461 & 0.105 & 343 & $1.48 e+4$ & 0.366 \\
\hline $3.11 e-5$ & 2.0 & 168 & 0.337 & 0.093 & 305 & $1.08 \theta+4$ & 0.391 \\
\hline $3.11 e-5$ & 7.0 & 114 & 0.799 & 0.131 & 432 & $2.57 \theta+4$ & 0.340 \\
\hline $2.485 \theta-5$ & 7.0 & 108 & 0.760 & 0.109 & 448 & $3.06 \theta+4$ & 0.309 \\
\hline $2.485 e-5$ & 6.0 & 114 & 0.686 & 0.105 & 433 & $2.76 \theta+4$ & 0.318 \\
\hline $2.485 e-5$ & 5.0 & 122 & 0.608 & 0.101 & 414 & $2.44 \theta+4$ & 0.329 \\
\hline $2.485 e-5$ & 4.0 & 132 & 0.529 & 0.095 & 392 & $2.130+4$ & 0.336 \\
\hline $2.485 e-5$ & 3.0 & 134 & 0.404 & 0.086 & 353 & $1.620+4$ & 0.355 \\
\hline $2.485 e-5$ & 7.0 & 106 & 0.744 & 0.109 & 447 & $2.99 \theta+4$ & 0.314 \\
\hline
\end{tabular}


Table 4. Data from tests with nozzle insert 3.

\begin{tabular}{|c|c|c|c|c|c|c|c|}
\hline$\dot{m}\langle\mathrm{~kg} / \mathrm{s}\rangle$ & Current, A & Voltage, V & Power (kW) & Thrust (N) & Isp (s) & $\mathrm{P} / \dot{\mathrm{m}} \quad(\mathrm{kJ} / \mathrm{kg})$ & Efficiency \\
\hline $4.97 e-5$ & 7.0 & 116 & 0.814 & 0.178 & 365 & $1.64 \theta+4$ & 0.375 \\
\hline $4.97 e-5$ & 4.0 & 135 & 0.542 & 0.148 & 304 & $1.09 \theta+4$ & 0.384 \\
\hline $4.97 e-5$ & 10.0 & 108 & 1.077 & 0.204 & 418 & $2.17 e+4$ & 0.376 \\
\hline $4.97 e-5$ & 9.0 & 111 & 0.997 & 0.196 & 402 & $2.01 \theta+4$ & 0.375 \\
\hline $4.97 e-5$ & 8.0 & 114 & 0.914 & 0.188 & 386 & $1.84 \theta+4$ & 0.375 \\
\hline $4.97 e-5$ & 7.0 & 118 & 0.829 & 0.179 & 367 & $1.67 e+4$ & 0.373 \\
\hline $4.97 e-5$ & 6.0 & 124 & 0.742 & 0.170 & 349 & $1.49 \theta+4$ & 0.375 \\
\hline $4.97 e-5$ & 5.0 & 130 & 0.649 & 0.161 & 330 & $1.300+4$ & 0.380 \\
\hline $4.97 e-5$ & 4.0 & 139 & 0.558 & 0.151 & 310 & $1.12 \theta+4$ & 0.388 \\
\hline $4.97 e-5$ & 3.0 & 154 & 0.462 & 0.140 & 288 & $9.300+3$ & 0.400 \\
\hline $3.73 e-5$ & 4.0 & 125 & 0.499 & 0.120 & 329 & $1.34 \theta+4$ & 0.371 \\
\hline $3.73 e-5$ & 10.0 & 99 & 0.987 & 0.165 & 451 & $2.65 e+4$ & 0.361 \\
\hline $3.73 e-5$ & 9.0 & 101 & 0.911 & 0.159 & 434 & $2.44 \theta+4$ & 0.360 \\
\hline $3.73 e-5$ & 8.0 & 105 & 0.836 & 0.153 & 417 & $2.24 \theta+4$ & 0.362 \\
\hline $3.73 e-5$ & 7.0 & 109 & 0.761 & 0.146 & 398 & $2.04 \theta+4$ & 0.362 \\
\hline $3.73 e-5$ & 6.0 & 114 & 0.686 & 0.139 & 381 & $1.84 \theta+4$ & 0.366 \\
\hline $3.73 e-5$ & 6.0 & 111 & 0.667 & 0.138 & 376 & $1.790+4$ & 0.367 \\
\hline $3.73 \theta-5$ & 6.0 & 110 & 0.661 & 0.137 & 374 & $1.77 \theta+4$ & 0.366 \\
\hline $3.73 \theta-5$ & 5.0 & 118 & 0.588 & 0.130 & 355 & $1.58 \theta+4$ & 0.368 \\
\hline $3.73 e-5$ & 5.0 & 115 & 0.575 & 0.128 & 351 & $1.54 \theta+4$ & 0.368 \\
\hline $3.73 \theta-5$ & 4.0 & 124 & 0.496 & 0.121 & 330 & $1.330+4$ & 0.375 \\
\hline $3.11 \theta-5$ & 7.0 & 100 & 0.703 & 0.123 & 404 & $2.26 \theta+4$ & 0.336 \\
\hline $3.11 e-5$ & 6.0 & 106 & 0.635 & 0.118 & 386 & $2.04 \theta+4$ & 0.339 \\
\hline $3.11 e-5$ & 5.0 & 112 & 0.558 & 0.112 & 366 & $1.790+4$ & 0.347 \\
\hline $2.485 e-5$ & 7.0 & 94 & 0.660 & 0.104 & 426 & $2.66 \theta+4$ & 0.321 \\
\hline $2.485 e-5$ & 6.0 & 99 & 0.593 & 0.099 & 407 & $2.39 \theta+4$ & 0.325 \\
\hline
\end{tabular}

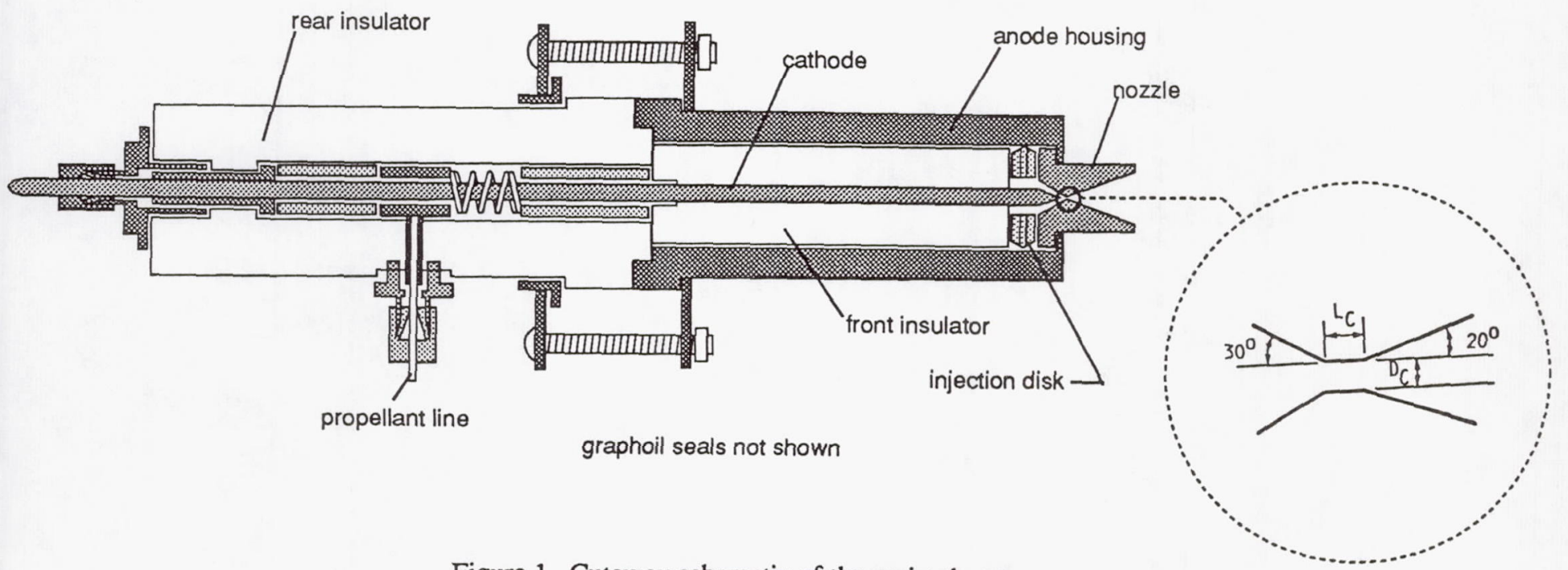

Figure 1. Cutaway schematic of the arcjet thruster. 


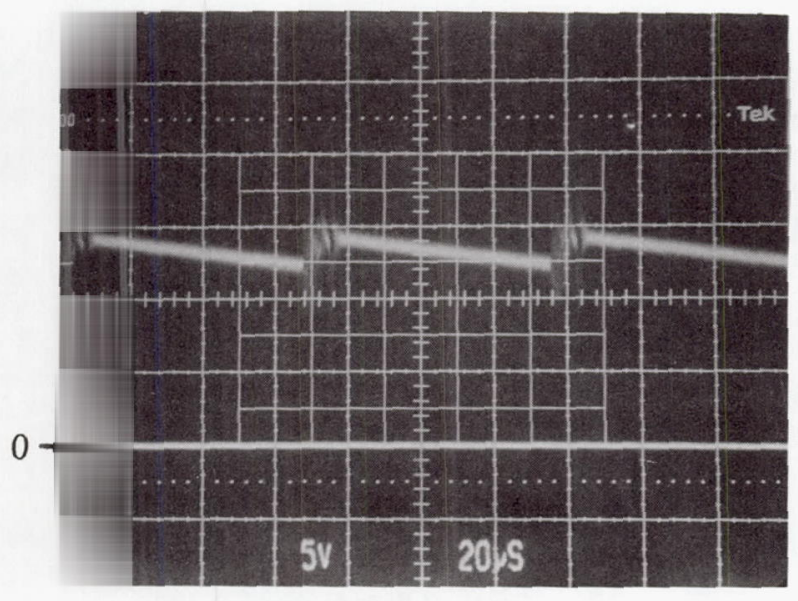

(a) 2 amperes

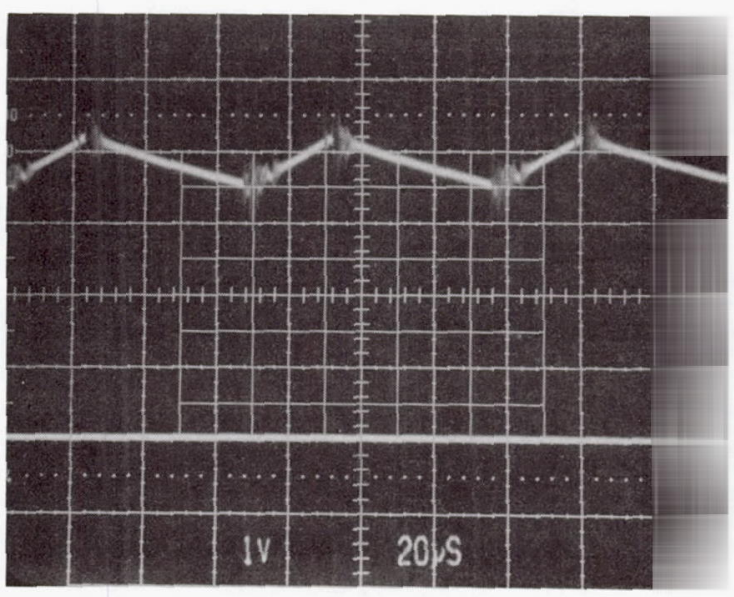

(b) 7 amperes

Figure 2. Oscilloscope traces showing current ripple.

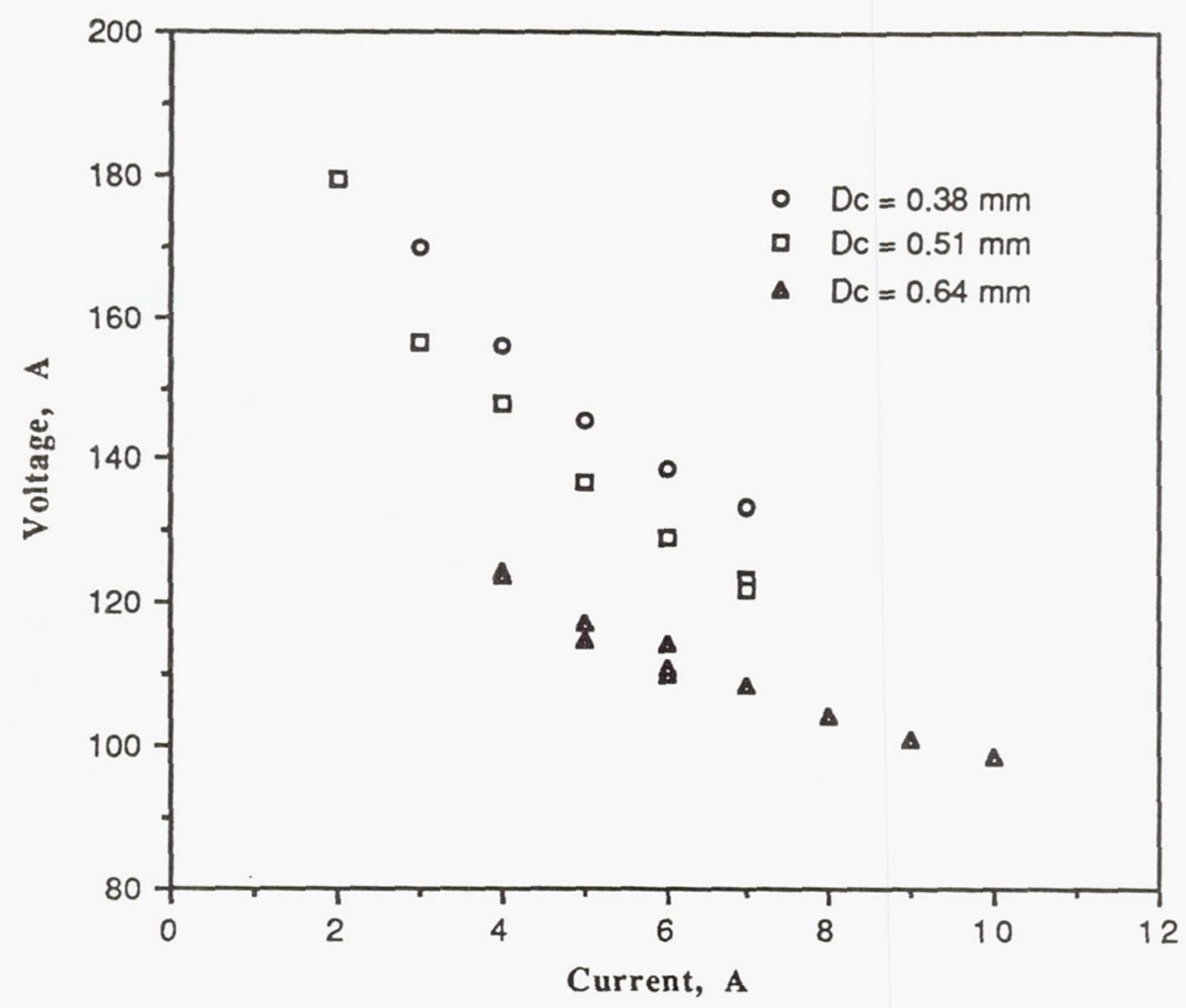

Figure 3. - Current-voltage characteristics ( $m=3.73 \mathrm{E}-5 \mathrm{~kg} / \mathrm{s}$ ) 


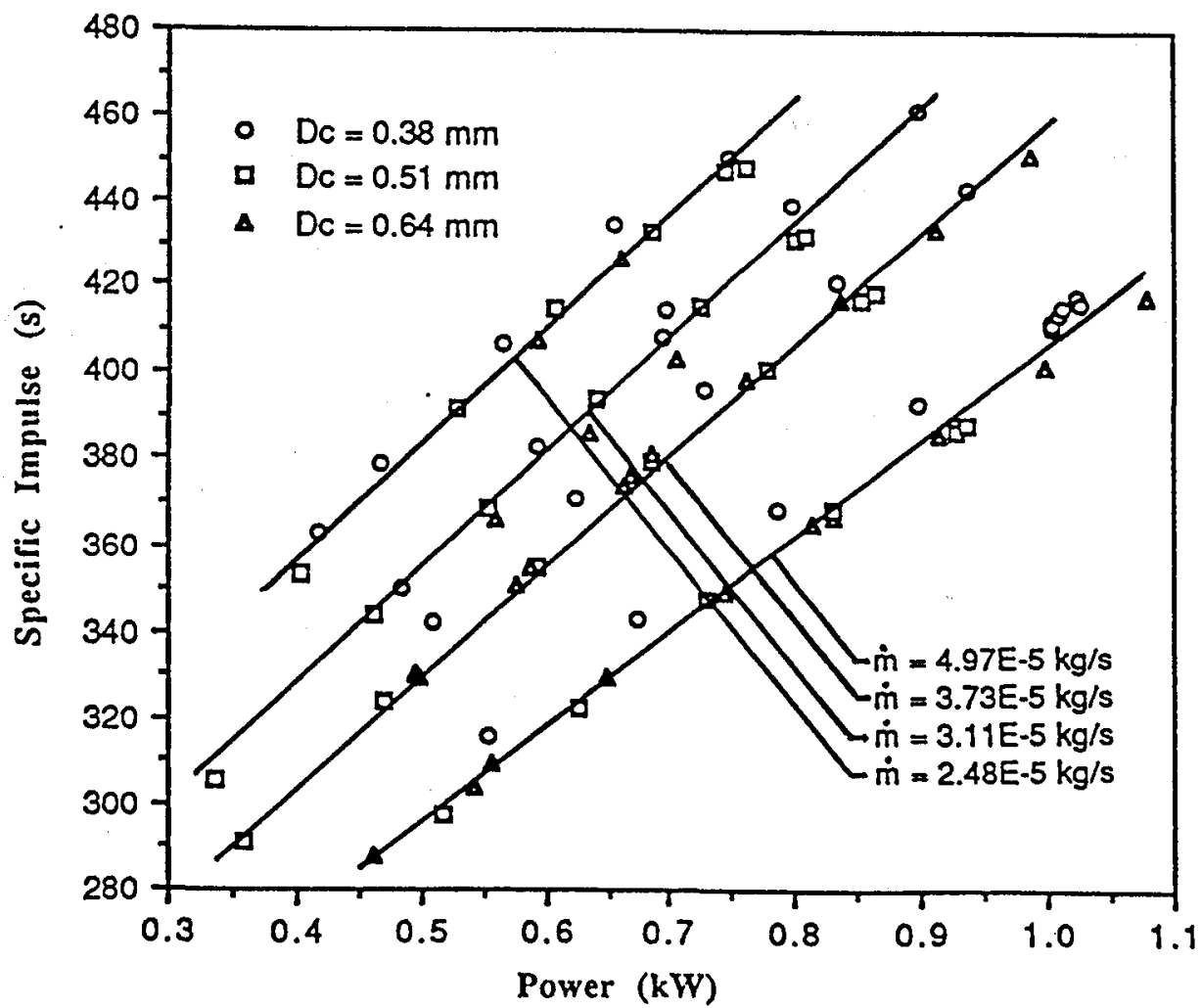

Figure 4. - Specific impulse versus power - all cases. 


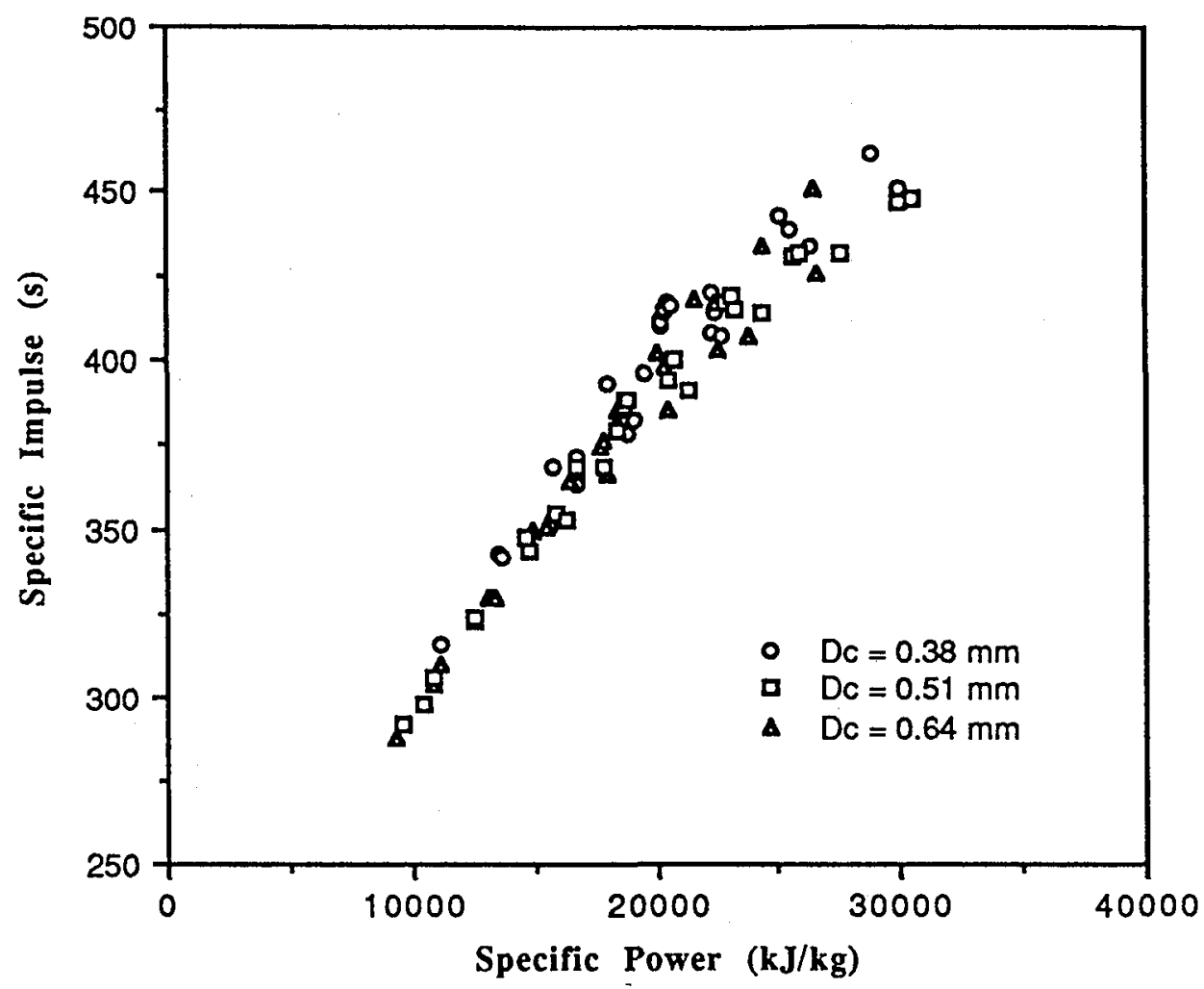

(a) All cases.

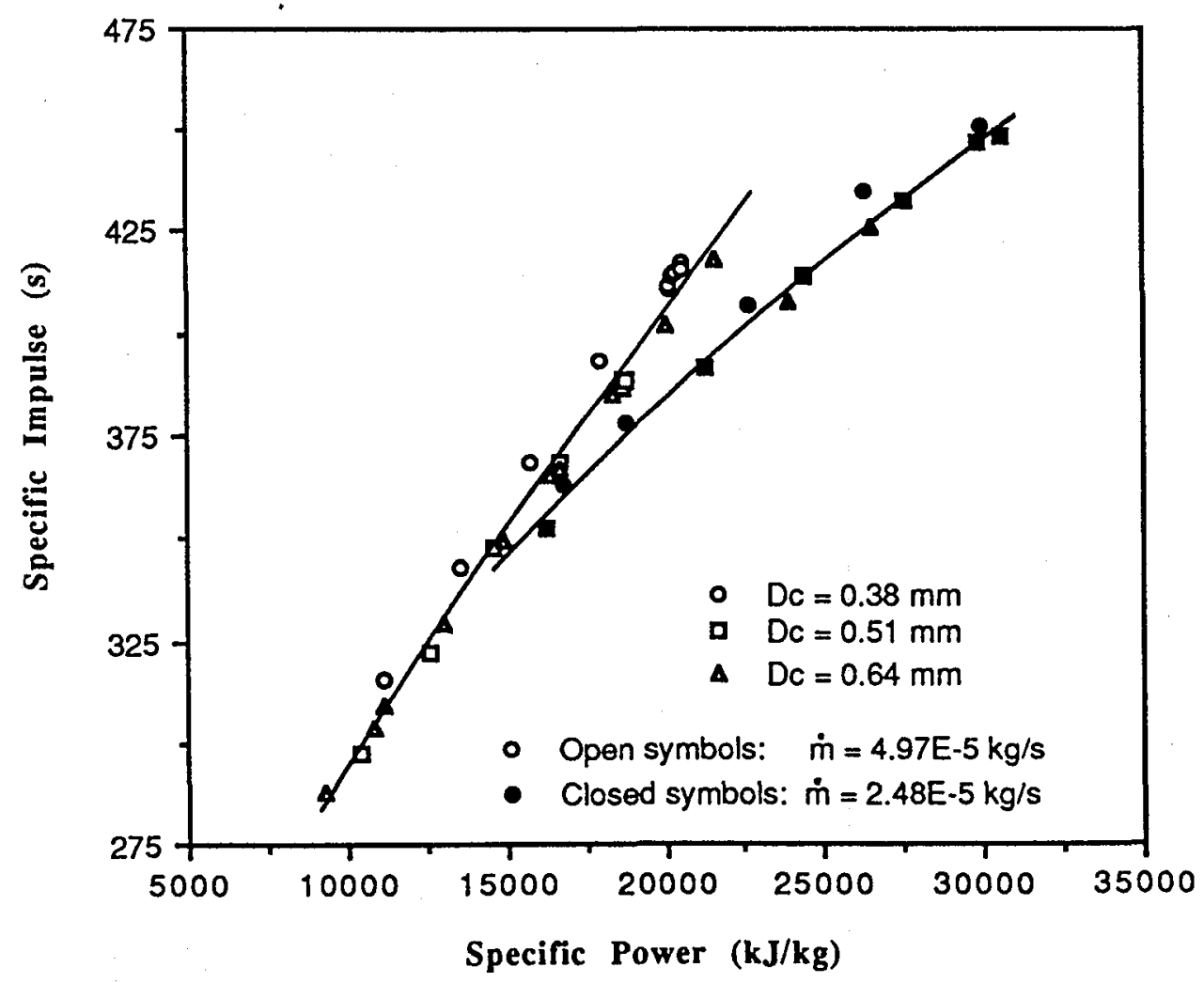

(b) Highest and lowest mass flow rates only.

Figure 5. - Specific impulse versus specific power. 


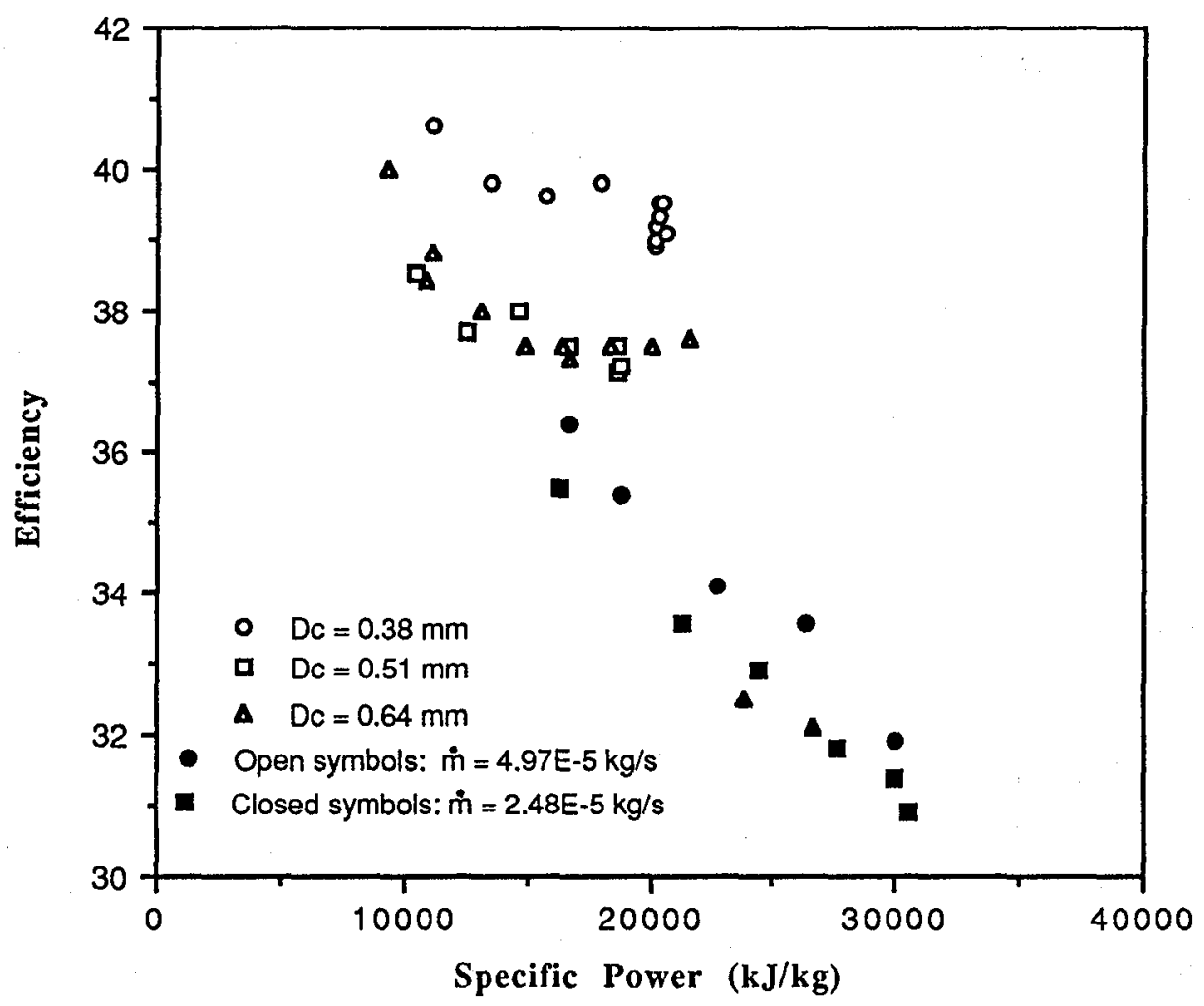

Figure 6. - Efficiency versus specific power - highest and lowest mass flow rates. 


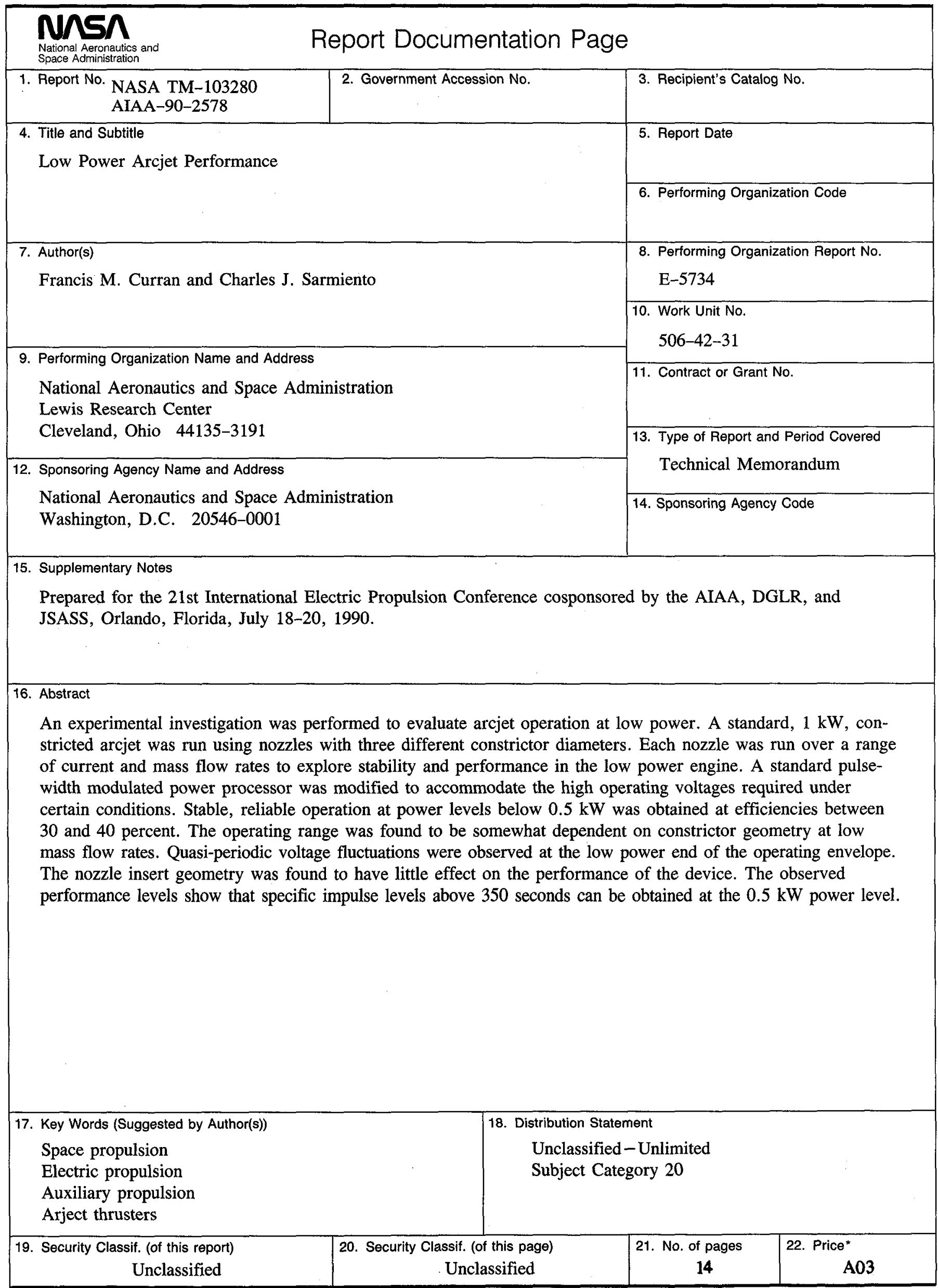


National Aeronautics and

Space Administration

Lewis Research Center

Cleveland, Ohio 44135

Official Business

Penalty for Private Use $\$ 300$
FOURTH CLASS MAIL

ADDRESS CORRECTION REQUESTED

age and Fees Paid

National Aeronautics and

Space Administration

NASA 45 